\title{
The impact of residual growth on deformity progression
}

\author{
Ismat Ghanem $^{1,2}$, Maroun Rizkallah ${ }^{1}$ \\ ${ }^{1}$ Faculty of Medicine, Saint-Joseph University, Beirut, Lebanon; ${ }^{2}$ Department of Orthopedic Surgery, Hôtel-Dieu de France University Hospital, \\ Saint-Joseph University, Beirut, Lebanon \\ Contributions: (I) Conception and design: All authors; (II) Administrative support: I Ghanem; (III) Provision of study materials or patients: All authors; \\ (IV) Collection and assembly of data: All authors; (V) Data analysis and interpretation: All authors; (VI) Manuscript writing: All authors; (VII) Final \\ approval of manuscript: All authors. \\ Correspondence to: Maroun Rizkallah. Department of Orthopedic Surgery, Hôtel-Dieu de France Hospital, Saint Joseph University, Alfred Naccache \\ Street, Achrafieh, Beirut, Lebanon. Email: maroun.rizkallah@gmail.com.
}

\begin{abstract}
Idiopathic scoliosis is a disease of the growing spine. Risk of progression and aggravation of disease are mainly dictated by the remaining growth and curve magnitude. Remaining growth can be estimated by repeated biometric measurements, tanner sign and bone age estimation. Puberty is the turning point in the natural history of this disease. The first two years following puberty are the turning point in the natural history of this disease since $90 \%$ of growth occurs during this period. Lateral olecranon radiograph is effective for estimating bone age during this phase. Growth acceleration is followed by a deceleration phase of three years where menarche occurs. Bone age during this phase is evaluated by hand X-rays and the Risser sign. Progression risk assessment of idiopathic scoliosis showed that a $30^{\circ}$ curve at the beginning of puberty together with $20^{\circ}$ to $30^{\circ}$ curves with more than $10^{\circ}$ of annual curve progression has a $100 \%$ risk of progression towards the $45^{\circ}$ surgical threshold. In these patients, anticipation may be the key for effective treatment strategy. Treating these curves earlier than the surgical threshold before increased stiffness would lead to a better outcome.
\end{abstract}

Keywords: Idiopathic scoliosis; puberty; growth spurt; anticipation; bone age

Submitted Oct 08, 2019. Accepted for publication Nov 11, 2019.

doi: 10.21037/atm.2019.11.67

View this article at: http://dx.doi.org/10.21037/atm.2019.11.67

\section{Introduction}

Idiopathic scoliosis is a disorder of the growing spine (1). This disease has a heterogeneous natural history with some patients presenting with rapidly progressive curves and others progressing indolently (2). The main risk factor for curve progression is the remaining growth (3). Other risk factors include sex, initial curve severity, and location of the deformity (3). Remaining growth and maturity are major parameters that should be taken into account when assessing a patient presenting with scoliosis (4-6). However, growth is not a monotonous process, it has periods of acceleration and deceleration; with puberty being the major turning point (7). Progression of idiopathic scoliosis correlates therefore with skeletal growth, peaking during growth spurt and slowing at skeletal maturity (8). Maturity indicators include chronological age, biometric variables, menarche, secondary sexual characteristics development and bone age (9). A spine surgeon should know how to measure and analyze these parameters in order to offer his patient the best available treatment, at the right time (1). Of note, surgery is recommended in adolescents with a curve magnitude of more than 45 to 50 degrees (10), and in patients with clinically significant deformities or deformities that are more likely to progress (10). Knowing the risk factors for curve progression may aid physicians anticipate the evolution of their patients' curves (11). This will help them establish a solid treatment strategy and would sometimes lead to an early spinal fusion to avoid a guaranteed curve progression and insure a better correction (11). 
Table 1 A checklist with 11 questions a spine surgeon should ask to have a complete assessment of the growth status of a patient presenting with idiopathic scoliosis

Questions that the spine surgeon should ask while assessing a children with idiopathic scoliosis

How tall is the child?

What is the child's sitting height?

How long is the subischial leg length?

How much has the child grown in a single year?

What is the child's chronologic age?

What is the bone age?

How much growth does the child have left in the trunk and in the lower limbs?

Exactly what point has the child reached on his or her developmental peak?

Where is the child in relation to puberty and the pubertal peak?

What about the Tanner signs?

How much does the child weigh?

\section{Puberty, the landmark of growth}

Puberty is the transitional period from childhood through the secondary sexual characteristics development to the achievement of final height (12). During this period, pubertal growth spurt causes an increase in spinal deformity $(11,13-17)$. Predicting timing and magnitude of growth spurt is of paramount importance to predict scoliosis curve progression, and therefore to propose timely treatment (13). Puberty starts insidiously and therefore, children should be closely followed up during this period (1). Puberty is a bi-phased process. The first phase, the acceleration phase, starts at bone age of 11 in girls and 13 in boys (4). Its first stigmata is the increase in growth velocity (standing height) to greater than $0.5 \mathrm{~cm}$ per month, or greater than 6 and $7 \mathrm{~cm} /$ year in girls and boys respectively $(8,18)$. The appearance of secondary sexual characteristics with the first appearance of pubic hair, the swelling of the testicles and the budding of the nipples (tanner stage 2) are another stigmata signing the beginning of puberty $(19,20)$. This phase characterized by rapid growth lasts for 2 years and is followed by a steady decrease in growth rate (4). This deceleration phase lasts 3 more years (1). Menarche occurs during the deceleration phase (4). The lower limbs stop growing after menarche, and no growth at all is noted 2 years following menarche (4). Once the kickoff of puberty is documented, the children should be examined at 6 months regular intervals where measurements should be repeated, noted and analyzed. Each visit should include a thorough interrogatory with a detailed physical exam: Biometric measurements for growth monitoring, assessment of secondary sexual characteristics, bone age evaluation for estimation of remaining growth. All these are necessary steps to assess curve progression and the patient's scoliotic risk (Table 1).

\section{Biometric measurements: twice annually to monitor growth.}

Different body dimensions have their own typical growth pattern but all follow the distal to proximal growth maturity gradient: body parts that are more distal will have their pubertal growth spurt earlier, following the same sequence in all children (6,21-23). Foot length is the body dimension with the earliest pubertal growth spurt (13). This is important on the first visit as patients' parents may easily recall the change of the shoe size of their child (24).

However, the four most important biometric measurements for growth monitoring are:

Standing height: this marker constitutes the sum of two sub-markers: sitting height and sub-ischial height. Both regions grow at different velocities. Therefore, standing height cannot easily account for the loss of trunk height in children with severe spinal deformity $(1,4)$. Standing height is preferably measured in centimeters with the patient standing on a stadiometer with shoes and socks off. The children are encouraged to stretch out to the maximum height with the application of a gentle upward pressure 
under the mastoid processes, with the examiner watching to confirm that the heels were not off the ground (5).

Sitting height: correlates strictly with trunk height. This is measured in centimeters, using a rigid wooden stool sufficiently high that the feet of the child could not reach the floor (5). When spinal deformity is diagnosed, a loss of sitting height is correlated to the severity of this deformity. A gain in sitting height of 12 to $13 \mathrm{~cm}$ occurs in puberty $(4,21)$.

Arm span: being relatively constantly correlated to standing height, (arm span $=97 \%$ of standing height throughout puberty and into adulthood) this measurement is helpful in estimating standing height in non-ambulatory children. This is measured in $\mathrm{cm}$ from the ends of the middle finger in one hand to the other with arms maximally outstretched (5). The rule is that arm span divided by 2 gives an idea of sitting height, and divided by 4 gives an idea of T1-S1 segment $(1,25)$.

Weight: during pubertal spurt, weight usually doubles. The gain is estimated to be $5 \mathrm{~kg}$ by year of puberty. Weight has to be at least $40 \mathrm{~kg}$ for the pubertal spurt to be normal $(4,25)$.

These measures should be performed at six months interval, with one measurement preferably performed near the child's birthday, during the same period of the day (13). The maximum growth rate is called peak height velocity (PHV), and the corresponding age called the peak growth age (PGA) (6). Girls have PHV of $8 \mathrm{~cm} /$ year $\pm 1 \mathrm{~cm}$ and boys have a PHV of $9 \mathrm{~cm} /$ year $\pm 1.5 \mathrm{~cm}(6,26)$.

\section{Bone age, a radiographic tool to estimate remaining bone growth}

Bone age is different from chronological age in around half of children. Accurate determination of bone age is a must as this will help estimate remaining bone growth and therefore curve progression in children with adolescent idiopathic scoliosis $(4,11,27)$.

Accelerating phase of growth starts at bone age 11 in girls and 13 in boys (1). One of its first signs clearly visible on anteroposterior radiographs of the hand is the ossification of the sesamoid bone of the thumb (1). Ossification of the triradiate cartilage occurs at 12 and 14 years of bone age in girls and in boys, respectively (21). This corresponds to the mid-point of the acceleration phase (21). The acceleration phase ends at the ages of 13 and 15 in girls and boys respectively (1). This relates with the elbow physis closure (28).
Any skeletal region with consistent physeal markers can be used to determine skeletal age (13). The most commonly used markers of bone age in patients with adolescent idiopathic scoliosis are the hand, the wrist, the elbow and the iliac apophysis (13).

The Risser sign, evaluating the stage of ossification of the iliac apophysis, is the most commonly used method to determine skeletal maturity in patients with adolescent idiopathic scoliosis (5). It was originally described in 1958 (29). However, Risser sign was shown to be poorly correlated to the acceleration phase of growth in puberty (5). Two-thirds of puberty, i.e., most of the growth and subsequently any curve progression, occur before Risser stage 1 as iliac apophysis begins to show ossification around 18 to 24 months following the beginning of puberty $(5,30,31)$.

The Greulich and Pyle index is also widely used for determination of bone age and maturity (32). It is limited by being widely spaced in time during the critical period of growth spurt (5). Furthermore, hand and wrist $\mathrm{X}$-rays are difficult to assess in the acceleration phase of puberty (1).

The Tanner-whitehouse III RUS score based on hand and wrist $\mathrm{x}$-rays was shown to strongly predict the acceleration phase of growth (5). The Sanders method for assessment of bone age introduced in 2008 is derived from the Tanner-whitehouse III RUS score (30). It is based on radiographic analysis of fingers and metacarpals (30). Eight stages are identified. Stages 1 and 2 correspond to prepubertal period, stages 3 and 4 correspond to the growth acceleration phase (Risser grade 0), and stages 5 to 8 cover Risser stages 1 to 5 until full skeletal maturity $(30,33)$. This method was shown to be reliable and to correlate more strongly with idiopathic scoliosis curve behavior than Risser sign and Greulish and Pyle atlas (1).

In 1962, Sauvegrain et al. developed a method to assess skeletal maturity using anteroposterior and lateral radiographs of the left elbow (28). Elbow radiographs provide useful information from bone age 10 to 13 years and 12 to 15 years in girls and boys respectively $(28,34)$. This method was simplified by Dimeglio et al. in 2005 who showed that the morphology of the olecranon apophysis on lateral elbow radiographs goes through five distinct appearances at 6 months intervals (Figure 1) (4,34,35). This is clinically significant because it happens between 11 and 12.5 years of bone age in girls and 13 and 15.5 years of bone age in boys, when the Risser sign is still at stage 0 (1).

Both Dimeglio and Sanders methods were shown to have a modest learning curve and an ease of clinical 

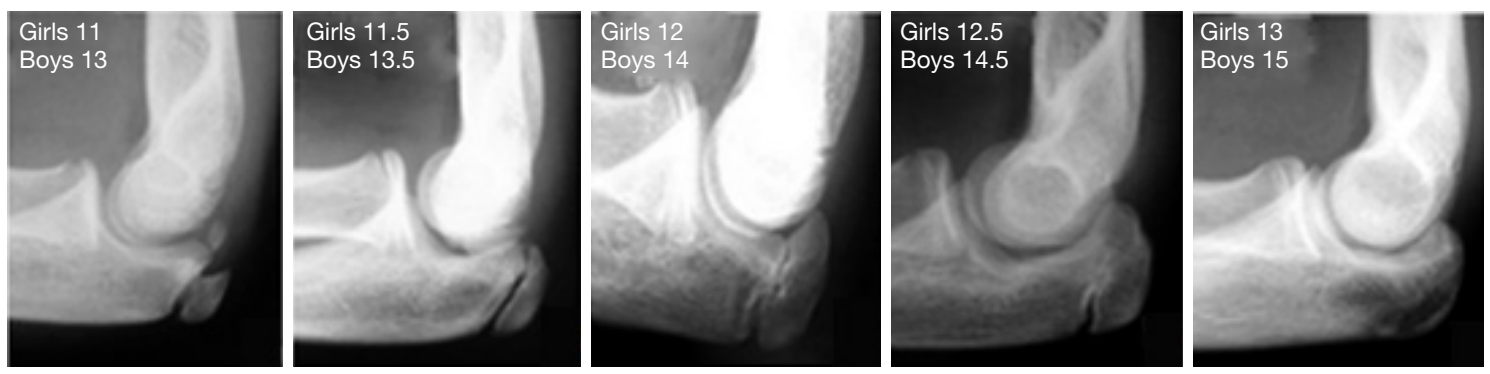

Figure 1 Figure showing the simplified Dimeglio's method of skeletal age assessment. (A) Two ossification nuclei (11 years in girls and 13 years in boys), (B) half-moon image (11.5 years in girls and 13.5 years in boys), (C) rectangular aspect (12 years in girls and 14 years in boys), (D) beginning fusion (12.5 years in girls and 14.5 years in boys), (E) complete fusion (13 years in girls and 15 years in boys).

application. Both methods, when compared, were equally reliable with a correlation that was equally strong for boys and girls (35). Therefore, lateral elbow radiograph is effective when assessing skeletal maturity during the pubertal growth spurt. A hand radiograph is preferable prior to puberty and from Risser grade 1 to 5 . A combination of both methods adequately covers the gap between elbow fusion and Risser grade 1, as one complements the other (35).

\section{The art of anticipation; how to assess the scoliotic risk}

The onset of the pubertal growth spurt is one main predictor for scoliotic curve progression in patients with adolescent idiopathic scoliosis $(1,3,4,8,36)$. Repetitive biometric measurements, attentive secondary sexual characteristics evaluation and radiographic bone skeletal maturity assessment estimate the remaining growth, and therefore help the spine surgeon predict the main scoliotic curve evolution $(1,3,4,36)$. Risk of progression is high during acceleration phase, and then decreases progressively from Risser stages 1 to 5 (1).

Another main predictor of progression is the curve magnitude $(7,9,11,37,38)$. The more severe the main curve is at the beginning of the growth spurt, the more important is the predicted progression $(7,9,11,37,38)$. Mainly, a scoliotic patient with a main curve cobb angle greater than 25 to 30 degrees is at significant risk of progression $(7,9,11,37,38)$.

Other predictors shown to influence curve progression in idiopathic scoliosis patients are sex and curve location, with thoracic curves being at higher risk of progression than lumbar curves (11).
Knowing that the surgical treatment threshold is set at 45 to 50 degrees, an accurate prediction of curve's progression becomes important. Taking the two major risk factors for curve progression into consideration (curve magnitude and remaining growth) lead to the following estimation: during the acceleration phase of puberty a $5^{\circ}$ curve is associated with a $10 \%$ risk of progression for surgery, a $10^{\circ}$ curve with a $20 \%$ risk of progression, a $20^{\circ}$ curve with a $30 \%$ risk of progression, and a $30^{\circ}$ curve raises the risk to virtually $100 \%(4,11,31,36,38)$. During the deceleration phase, the risk of progression is lower. At Risser stage I there is a $10 \%$ risk of progression for a $20^{\circ}$ curve and a $60 \%$ risk for a $30^{\circ}$ curve; at Risser sign stage II there is a $2 \%$ risk for a $20^{\circ}$ curve and $30 \%$ risk for a $30^{\circ}$ curve; at Risser stage III there is a $12 \%$ risk of progression for a curve of $\geq 20^{\circ}$; at Risser sign IV the risk of progression is markedly decreased; at Risser sign V skeletal maturity has been reached $(1,4)$.

Charles et al. showed that in patients with main thoracic scoliotic curves exceeding $30^{\circ}$ at the beginning of puberty, the risk of progression to the surgical threshold is nearly $100 \%$. In patients with curves ranging from $21^{\circ}$ to $30^{\circ}$, the risk of progression to surgery fluctuates from $30 \%$ to $75 \%$. Patients in this section need to be closely monitored, especially in the ascending accelerating phase of puberty, and their annual curve progression velocity should be calculated. An increase of less than $6^{\circ}$ per year is reassuring. An increase of $6^{\circ}$ to $10^{\circ}$ per year is associated to $70 \%$ of evolution to surgery. An increase of more than $10^{\circ}$ per year or more than $1^{\circ}$ per month represents a $100 \%$ risk of evolution towards surgery $(1,4,11,38)$.

These observations led to the concept of anticipation based on individual scoliotic risk $(1,4,11,38)$. Waiting for the patient with idiopathic scoliosis to reach and exceed the surgical threshold may lead to stiff and severe curves 
$(1,4,11,38)$. These curves would be difficult to correct, leading to only partial reduction $(1,4,11,38)$. An earlier intervention at earlier stages based on the anticipation of reaching the surgical threshold in the months to come, could be more advantageous, allowing an easier curve reduction $(1,4,11,38)$. This is still a theoretical conclusion based on retrospective studies as no higher level studies have been performed on this subject $(11,38)$. Operating patients in their growth spurt is associated with the risks of the crankshaft phenomenon and the deficit of trunk growth (4). Crankshaft phenomenon can be avoided by waiting for the closure of the triradiate cartilage that usually happens in the year that follows the beginning of puberty $(39,40)$, and by a complete curve correction with a reduction of the cobb angle to $0^{\circ}$ (4). The deficit on the trunk growth that occurs with early fusion will be balanced by the correction of the deformity as the remaining growth on the thoracic spine is 3.6 and $3.9 \mathrm{~cm}$ in girls and boys respectively and the remaining growth on the lumbar spine in 2.1 and $2.3 \mathrm{~cm}$ in girls and boys respectively (4).

\section{Conclusions}

Idiopathic scoliosis is a dynamic disease of the growing spine strongly correlated to the remaining growth potential. An accurate production of the curve progression, when possible, is paramount and would modify the treatment strategy. Besides the curve magnitude, remaining growth is essential for analyzing possible curve progression. Radiographic assessment of bone age (skeletal maturity), evaluation of secondary sexual characteristics, and regular biannual biometric measures help accurately estimate remaining bone growth. Acceleration phase of puberty starts at 11 and 13 years of bone age in girls and boys respectively. It lasts for 2 years during which the majority of growth, and $90 \%$ of curve progression, occur. In this phase, lateral elbow radiograph is the best way to assess bone age. This phase is followed by the descending phase lasting 3 years in which Risser sign and hand $\mathrm{X}$-rays are preferable for bone age assessment. Curves of more than $30^{\circ}$ at the beginning of the growth spurt and those between $20^{\circ}$ and $30^{\circ}$ with more than $10^{\circ}$ of annual curve progression are at nearly $100 \%$ risk of progression to surgery. In these patients, anticipation is the key for an effective treatment strategy, where aggressive scoliosis should be treated before it is too late to get the best outcome.

\section{Acknowledgments}

None.

\section{Footnote}

Conflicts of Interest: The authors have no conflicts of interest to declare.

Ethical Statement: The authors are accountable for all aspects of the work in ensuring that questions related to the accuracy or integrity of any part of the work are appropriately investigated and resolved.

\section{References}

1. Dimeglio A, Canavese F. Progression or not progression? How to deal with adolescent idiopathic scoliosis during puberty. J Child Orthop 2013;7:43-9.

2. Newton Ede MMP, Jones SW. Adolescent idiopathic scoliosis: evidence for intrinsic factors driving aetiology and progression. Int Orthop 2016;40:2075-80.

3. Lonstein JE, Carlson JM. The prediction of curve progression in untreated idiopathic scoliosis during growth. J Bone Joint Surg Am 1984;66:1061-71.

4. DiMeglio A, Canavese F, Charles YP. Growth and adolescent idiopathic scoliosis: when and how much? J Pediatr Orthop 2011;31:S28-36.

5. Sanders JO, Browne RH, McConnell SJ, et al. Maturity assessment and curve progression in girls with idiopathic scoliosis. J Bone Joint Surg Am 2007;89:64-73.

6. Sanders JO. Maturity indicators in spinal deformity. J Bone Joint Surg Am 2007;89 Suppl 1:14-20.

7. Duval-Beaupère G, Lamireau T. Scoliosis at less than 30 degrees. Properties of the evolutivity (risk of progression). Spine (Phila Pa 1976) 1985;10:421-4.

8. Little DG, Song KM, Katz D, et al. Relationship of peak height velocity to other maturity indicators in idiopathic scoliosis in girls. J Bone Joint Surg Am 2000;82:685-93.

9. Sitoula P, Verma K, Holmes L, et al. Prediction of Curve Progression in Idiopathic Scoliosis: Validation of the Sanders Skeletal Maturity Staging System. Spine (Phila Pa 1976) 2015;40:1006-13.

10. Altaf F, Gibson A, Dannawi Z, et al. Adolescent idiopathic scoliosis. BMJ 2013;346:f2508.

11. Charles YP, Daures J-P, de Rosa V, et al. Progression risk of idiopathic juvenile scoliosis during pubertal growth. 
Spine (Phila Pa 1976) 2006;31:1933-42.

12. Shim KS. Pubertal growth and epiphyseal fusion. Ann Pediatr Endocrinol Metab 2015;20:8-12.

13. Busscher I, Wapstra FH, Veldhuizen AG. Predicting growth and curve progression in the individual patient with adolescent idiopathic scoliosis: design of a prospective longitudinal cohort study. BMC Musculoskelet Disord 2010;11:93.

14. Cheung J, Veldhuizen AG, Halbertsma JPK, et al. The relation between electromyography and growth velocity of the spine in the evaluation of curve progression in idiopathic scoliosis. Spine (Phila Pa 1976) 2004;29:1011-6.

15. Yrjönen T, Ylikoski M. Effect of growth velocity on the progression of adolescent idiopathic scoliosis in boys. J Pediatr Orthop B 2006;15:311-5.

16. Ylikoski M. Height of girls with adolescent idiopathic scoliosis. Eur Spine J 2003;12:288-91.

17. Wever DJ, Tonseth KA, Veldhuizen AG. Curve progression and spinal growth in brace treated idiopathic scoliosis. Stud Health Technol Inform 2002;91:387-92.

18. Song KM, Little DG. Peak height velocity as a maturity indicator for males with idiopathic scoliosis. J Pediatr Orthop 2000;20:286-8.

19. Tanner JM, Whitehouse RH. Clinical longitudinal standards for height, weight, height velocity, weight velocity, and stages of puberty. Arch Dis Child 1976;51:170-9.

20. Karlberg J, Kwan C-W, Gelander L, et al. Pubertal growth assessment. Horm Res 2003;60:27-35.

21. Dimeglio A. Growth in pediatric orthopaedics. J Pediatr Orthop 2001;21:549-55.

22. Rao S, Joshi S, Kanade A. Growth in some physical dimensions in relation to adolescent growth spurt among rural Indian children. Ann Hum Biol 2000;27:127-38.

23. Iuliano-Burns S, Mirwald RL, Bailey DA. Timing and magnitude of peak height velocity and peak tissue velocities for early, average, and late maturing boys and girls. Am J Hum Biol 2001;13:1-8.

24. Ford KR, Khoury JC, Biro FM. Early markers of pubertal onset: height and foot size. J Adolesc Health 2009;44:500-1.

25. Dimeglio A, Canavese F. The growing spine: how spinal deformities influence normal spine and thoracic cage growth. Eur Spine J 2012;21:64-70.

26. Beunen G, Thomis M, Maes HH, et al. Genetic variance of adolescent growth in stature. Ann Hum Biol 2000;27:173-86.

27. Charles YP, Diméglio A, Marcoul M, et al. Influence of idiopathic scoliosis on three-dimensional thoracic growth. Spine (Phila Pa 1976) 2008;33:1209-18.
28. Sauvegrain J, Nahum H, Bronstein H. Study of bone maturation of the elbow. Ann Radiol (Paris) 1962;5:542-50.

29. Risser JC. The Iliac apophysis; an invaluable sign in the management of scoliosis. Clin Orthop 1958;11:111-9.

30. Sanders JO, Khoury JG, Kishan S, et al. Predicting scoliosis progression from skeletal maturity: a simplified classification during adolescence. J Bone Joint Surg Am 2008;90:540-53.

31. Charles YP, Diméglio A, Canavese F, et al. Skeletal age assessment from the olecranon for idiopathic scoliosis at Risser grade 0. J Bone Joint Surg Am 2007;89:2737-44.

32. Greulich WW, Pyle SI. Radiographic atlas of skeletal development of the hand and wrist. Am J Med Sci 1959;238:393.

33. Neal KM, Shirley ED, Kiebzak GM. Maturity Indicators and Adolescent Idiopathic Scoliosis: Evaluation of the Sanders Maturity Scale. Spine (Phila Pa 1976) 2018;43:E406-12.

34. Diméglio A, Charles YP, Daures JP, et al. Accuracy of the Sauvegrain method in determining skeletal age during puberty. J Bone Joint Surg Am 2005;87:1689-96.

35. Canavese F, Charles YP, Dimeglio A, et al. A comparison of the simplified olecranon and digital methods of assessment of skeletal maturity during the pubertal growth spurt. Bone Joint J 2014;96-B:1556-60.

36. Duval-Beaupere G, Dubousset J, Queneau P, et al. A unique theory on the course of scoliosis. Presse Med 1970;78:1141-6 passim.

37. Tan KJ, Moe MM, Vaithinathan R, et al. Curve progression in idiopathic scoliosis: follow-up study to skeletal maturity. Spine (Phila Pa 1976) 2009;34:697-700.

38. Charles YP, Canavese F, Diméglio A. Curve progression risk in a mixed series of braced and nonbraced patients with idiopathic scoliosis related to skeletal maturity assessment on the olecranon. J Pediatr Orthop B 2017;26:240-4.

39. Roberto RF, Lonstein JE, Winter RB, et al. Curve progression in Risser stage 0 or 1 patients after posterior spinal fusion for idiopathic scoliosis. J Pediatr Orthop 1997;17:718-25.

40. Sanders JO, Herring JA, Browne RH. Posterior arthrodesis and instrumentation in the immature (Rissergrade-0) spine in idiopathic scoliosis. J Bone Joint Surg Am 1995;77:39-45.

Cite this article as: Ghanem I, Rizkallah M. The impact of residual growth on deformity progression. Ann Transl Med 2020;8(2):23. doi: 10.21037/atm.2019.11.67 